\title{
10.0. \\ Dozer 'side-cutting' versus excavator side-casting on the highwall in dozer bulk push operations
} $\sum$ CAPACI OCCASIO $?$

\author{
by N. Sinclair* and M. Nehring*
}

\section{Synopsis}

In open pit dozer bulk push operations, the material left resting against the highwall after blasting poses an issue. This is because dozers cannot physically get in behind the waste to begin the bulk pushing process. Instead, an excavator can be used to side-cast this waste for the dozers to access. An alternative technique is to have the dozers 'side-cut' the material, which involves the dozers running parallel to the wall, digging out the material, and eventually rotating their blades to begin bulk pushing. Industry practices suggest the latter technique is less productive and economical than using an excavator. However, such excavator sidecasting 'economic viability' assumes that smaller/ancillary type excavators are used (i.e. less than $23 \mathrm{~m}^{3}$ bucket capacity). So, what happens if some mine sites are restricted to using relatively larger excavators $\left(>23 \mathrm{~m}^{3}\right.$ bucket) that are preferred for higher priority digging tasks? When can they avoid using their excavator? This paper explores multiple scenarios that have been designed and developed to simulate data results, which identify conditions in which the dozer side-cutting technique becomes more economically viable than excavator side-casting in terms of decreased unit cost per loose cubic metre.

Keywords

dozer push, excavator, side casting, side cutting.

\section{Introduction}

Optimizing the cost of waste removal operations is important for the profitability of opencast coal mines. In the past decade, dozer bulk pushing has emerged and taken over from traditional waste removal operations such as dragline and truck-and-shovel methods at various sites around the world (Beatty, 1994). In a typical bulk push operation, once the bench has been blasted, waste is left resting against the highwall, which can either be cleared using a loading unit or by having the dozers 'side-cut' the highwall.

Dozers perform most effectively when slot dozing side-by-side, perpendicular to the highwall. However, when dozers are required to remove material off the highwall, they must push parallel to the highwall, rather than perpendicular, hence 'side-cutting' the material to ensure a clean face. While dozer sidecutting is possible, it has been found that the majority of mine sites use a loading unit in this situation to avoid dozer inefficiency. Other perceived issues with dozer side-cutting include higher maintenance requirements and safety risks to dozer operators working in close proximity to the highwall.

overall, current industry practices surrounding dozer bulk push operations suggest that the use of an excavator on the highwall is more productive and economically viable than dozer side-cutting. This statement, however, is based on the assumption that small ancillary-type loading units are used (i.e. excavators smaller than $23 \mathrm{~m}^{3}$ bucket capacity). Hence, the use of an excavator on the highwall might not be more economically favourable for mine sites that own only large excavators preferred for high-priority digging rather than secondary trenching tasks in dozer bulk push processes.

An open cut thermal coal mine in the Hunter Valley in NSW, Australia (denoted as 'the mine site' throughout this paper) hired three D11R Caterpillar dozers specifically to perform bulk push operations on site for the first time. This mines' smallest excavator was a Hitachi EX3600 fitted with a $29 \mathrm{~m}^{3}$ bucket, with an effective utilization of $61 \%$. It was preferred for primary mining tasks instead of secondary trenching tasks, which is the reason why this particular mine was used as a case study for this project. It catered for the objective of this project, which was to determine situations in which the dozer sidecutting technique can be used cost-effectively instead of the excavator side-casting technique.

This was achieved by modelling and comparing the productivity of removing a waste bench using both techniques in terms of the following variables:

> Bench width

> Muckpile profile

> Material fragmentation

$>$ Excavator size.

* School of Mechanical and Mining Engineering, The University of Queensland, Australia.

(C) The Southern African Institute of Mining and Metallurgy, 2019. ISSN 2225-6253. Paper received Dec. 2017; revised paper received Jul. 2018. 


\section{Dozer 'side-cutting' versus excavator side-casting on the highwall in dozer bulk push operations}

Using these results, a decision matrix, outlining the variables and therefore the different possible conditions under which a cost-effective dozer push operation can take place, was developed. This serves as a practical tool for mining operations staff and engineers to use when deciding which technique to use. It will allow their decisions to be based on current studies; mine site data, and newly developed dozer push principles rather than past practices and rules of thumb. The cost model and the research methodology on which the decision matrix is based can be replicated for other mine sites with similar excavator constraints. Furthermore, the increased attention to the optimization of dozer bulk pushing processes can hopefully encourage additional research on this topic to further our understanding of this previously unexplored waste removal method.

\section{Dozer bulk push methodology and design}

\section{A typical dozer push bench profile}

A typical dozer bulk push profile is illustrated in Figure 1 (Ingles et al., 2005). It shows the aftermath of a cast blast. The top overburden bench is handled using dozer bulk push techniques that level the cast profile and reduce rehandling, thereby optimizing the dragline's performance when removing the lower overburden bench atop of the coal seam. The dozers bulk push in sections denoted by B, C, D, E, F, and $\mathrm{G}$, while an excavator is used to remove material off the highwall in sections denoted from $1 \mathrm{~B}$ to $6 \mathrm{G}$. The excavator side-casts material $12 \mathrm{~m}$ off the highwall to allow dozers to reverse over the excavated material and begin pushing into the spoils. Twelve metres is an industry rule of thumb, reflecting the length of a CAT D11R dozer (Hall, 2016).
Waste material that is cast or pushed straight into the waste dump is referred to as 'cast prime dirt' and is defined in Figure 2 by the waste dump angle of repose. Material above the waste dump angle of repose is left for the dragline to rehandle and cast into the waste dump itself (Cunningham, 2013).

\section{Dozer bulk push design}

A major design concept in bulk pushing operations is the concept of 'cut and fill' using a 'pivot point'. This is illustrated in Figure 2. The pivot point is the point where the blast profile intersects the desired waste dump (the final low wall). It is usually designed between $47^{\circ}$ and $53^{\circ}$ from the horizontal at the toe of the coal seam (Uren and Nehring, 2015). The pivot line designates the 'cut' and 'fill' sections. Material should be cut and pushed on the highwall side of the pivot point and then carried and dumped (filled) on the low wall side of the pivot point. The pivot point allows an efficient way of designing each 'push' phase of the dozer push cycle by cutting the blasted material into slices. Depending on how large the blast is, the more material that can be blasted and cast to lie behind the pivot line the better, as it is considered prime dirt (i.e. not to be rehandled).

\section{Previous industry case studies of excavator-assisted dozer push operations}

Recent published studies, including those of Uren and Nehring (2015) and Cunningham (2014), have looked into producing software for dozer push operations and optimizing dozer push operations as a whole. However, only limited studies have been conducted regarding the use of an excavator during bulk push operation. Nevertheless, one study conducted by Ingles et al (2005) provided results and

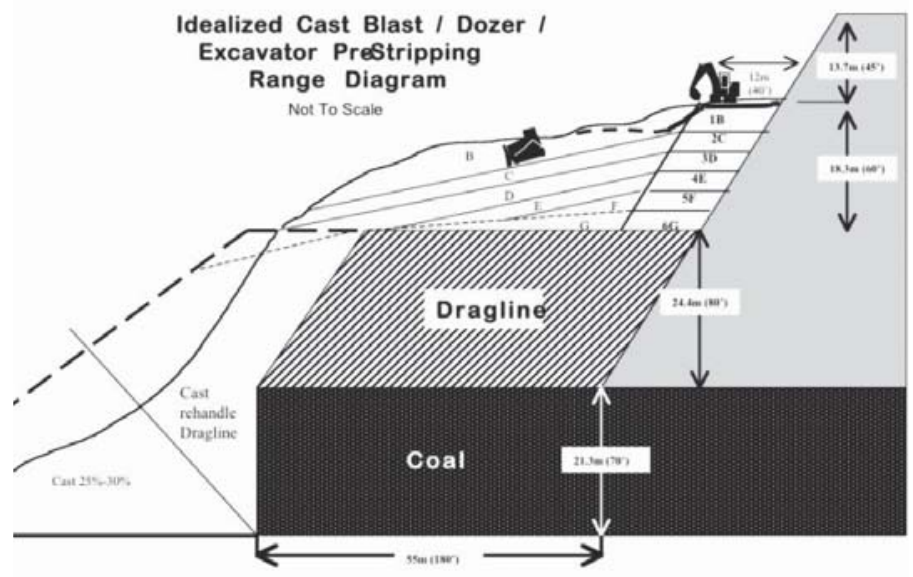

Figure 1-A typical dozer bulk push bench profile (Ingle et al., 2005)

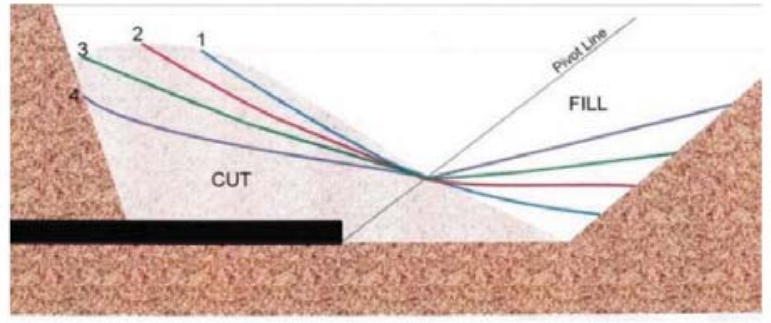

Figure 2-Dozer push 'cut and fill' design concept (MEC Mining, 2016) 


\section{Dozer 'side-cutting' versus excavator side-casting on the highwall in dozer bulk push operations}

methodology most relating to this research project. Similar studies by Caterpillar (2008) and JKMRC (1998) considered only the Caterpillar $5130 \mathrm{~b}$ excavator when comparing the productivity of bench removal using dozers and the excavator. However, both studies assumed that if the material left on the highwall was not removed by excavator, it was left for a dragline to remove. Unfortunately, no research was done regarding dozer productivity and costs specifically relating to side-cutting the material off the highwall.

\section{Field study and simulation by Ingles et al. (2005)}

Ingles et al. (2005) conducted a field study as well as simulation study to compare the productivity of Caterpillar $\mathrm{D} 11 \mathrm{R}$ dozers with and without excavator assistance. The simulation study considered the use of the dozer side-cutting technique.

For the field study, an area $30.5 \mathrm{~m}$ in width and $68.5 \mathrm{~m}$ in length was staked out on a downhill grade of $20 \%$ (Ingles et al., 2005). The first test required the machines to perform slot dozing in the area without removing the material along the highwall. The second test involved a Caterpillar 5230b mass excavator with a 14-yard bucket (equivalent to a Hitachi EX2600 200 t excavator) side-casting 783 loose cubic metres (LCM) of material from the highwall into the doze area. The dozers then reversed up and behind the side-casted material and began to push and doze that material perpendicular to the wall along with the material from their respective pits.

The simulation study using DOZIM software assumed the same bench profile as described above, as well as the following parameters:

> Dozer cast material: 306000 bank cubic metres (BCM)

> Loose weight: $2800 \mathrm{lb}$ per cubic yard

> Altitude: $2500-5000$ feet

> Job efficiency: $83 \%$ (53 $\mathrm{min} / \mathrm{h}$ )

> Skill level: $95 \%$

> Dozability: $100 \%$.

Furthermore, with the use of bucket size and typical sidecasting cycle times for excavators working on the highwall, the productivity for a hydraulic excavator was estimated. Figure 3 shows the inputs and productivity:
The results of the field study showed the average dozing production for the D11R was 2113 bcm per hour, which was approximately $20 \%$ less than for the excavator-assisted operation. The results of the first simulation test (without excavator assistance) indicated that the D11R dozer needed 420 hours in order to remove the cast dozer material. Out of these 420 hours, 122 hours was considered 'side-cutting' time, 191 hours was allocated to rehandling the highwall cut material, and 214 hours allocated to slot doze the remaining bench material. The average dozer productivity over the area was 700 LCM per hour. The results of the second simulation test (with excavator assistance) indicated that 306 hours of dozer pushing was required with 58 excavator hours occurring simultaneously. The excavator had a bucket capacity of $11.5 \mathrm{~m}^{3}$. Dozer productivity increased to 1000 LCM per hour. These simulation results suggested the productivity loss associated with having the dozers side-cut was approximately $30 \%$.

\section{Knowledge gap}

The literature review showed that the knowledge gap lay within several areas:

> Dozer bulk push is mostly considered as a pre-dragline bench removal method rather than a waste removal method in itself. This is why the majority of the industry case studies assumed the highwall material could be removed using a dragline.

- None of the industry studies involving the use of an excavator in the dozer bulk push process considered any excavators larger than $23 \mathrm{~m}^{3}$ bucket capacity (Caterpillar 5230b excavator).

> The relationship between dozer push productivity and fragmentation and muckpile profiles has not been extensively explored.

> No testing has been conducted or results published regarding the productivity loss when dozers side-cut the highwall during bulk pushing (a side-cutting production factor has not been established).

The following section describes the methodology followed in the research project in order to investigate these topics further and close the gap surrounding some unexplored dozer bulk push practices.

\begin{tabular}{|c|c|c|c|c|c|}
\hline Excavator & $375 \mathrm{BL}$ & $385 \mathrm{BL}$ & $5110 \mathrm{BL}$ & $5130 \mathrm{~B}$ & $5230 \mathrm{~B}$ \\
\hline $\begin{array}{l}\text { Average Cycle Time (min.) } \\
\text { (Includes Positioning and maintaining } \\
\text { the High wall) }\end{array}$ & 0.44 & 0.44 & 0.45 & 0.46 & 0.47 \\
\hline Cycles / $60 \mathrm{~min}$. Hr. & 136 & 136 & 133 & 130 & 128 \\
\hline Average Bucket Load (LCY) & 5.8 & 7.3 & 9.0 & 15.0 & 23.5 \\
\hline Average Bucket Load $\left(\mathrm{m}^{3}\right)$ & 4.4 & 5.5 & 6.9 & 11.5 & 18.0 \\
\hline Bucket Fill Factor & $105 \%$ & $105 \%$ & $105 \%$ & $105 \%$ & $105 \%$ \\
\hline Production / $60 \mathrm{~min}$. Hr. (LCY) & 823 & 1038 & 1260 & 2054 & 3150 \\
\hline Production / $60 \mathrm{~min} . \mathrm{Hr} .\left(\mathrm{m}^{3}\right)$ & 629 & 794 & 963 & 1571 & 2408 \\
\hline Swell Loose Dozer to Cast Bank & $12 \%$ & $12 \%$ & $12 \%$ & $12 \%$ & $12 \%$ \\
\hline Job Efficiency 50 Min Hour & $83 \%$ & $83 \%$ & $83 \%$ & $83 \%$ & $83 \%$ \\
\hline Resulting Cast Bank Cu Yds/ Hour & 610 & 769 & 934 & 1,522 & 2,334 \\
\hline Resulting Cast Bank Cu Meters/ Hr & 466 & 588 & 714 & 1,164 & 1,785 \\
\hline
\end{tabular}




\section{Dozer 'side-cutting' versus excavator side-casting on the highwall in dozer bulk push operations}

\section{Research project methodology Variables and assumptions}

In order to simulate the data to determine the cost-effective situations in which excavator side-cutting was preferred over dozer side-cutting, 109 different scenarios with various combinations of variables were designed. The different combinations are illustrated in Figures 7, 8, and 9 in the 'Design process' section of this paper. The four variables selected to model were bench width, fragmentation factor, muckpile profile, and excavator size. Using the literature and operator and industry testimonials, appropriate assumptions were made regarding the different levels within each variable.

\section{Bench width}

Typical bulk push operations occur on benches ranging from 45 to $60 \mathrm{~m}$ in width and 30 to $40 \mathrm{~m}$ in height (Boutlon, 2016). For the purposes of this research project, a bench height of $35 \mathrm{~m}$ was selected and kept constant as cost and productivity were deemed more sensitive to changes in bench width than to bench height. This is because bench width impacts directly on the distance dozers have to push perpendicular to the wall, which is a dominant production factor in dozer bulk push operations. Three different widths were selected: $45 \mathrm{~m}, 55 \mathrm{~m}$, and $60 \mathrm{~m}$. These dimensions were selected based on the bench widths used at the mine site as well as being typical bench widths for dragline and dozer push operations.

\section{Fragmentation factor}

The fragmentation of the waste material was categorized as fine, medium, and coarse. Table I outlines the information extracted from a graph by Hayes (1997) in order to gauge the dozer production loss associated with different material fragmentation. The majority of the push distances designed ranged between 50 and $100 \mathrm{~m}$, therefore the average productivity for medium and coarse fragmentation was found for push distances 60.9 and $91.4 \mathrm{~m}$. It is important to note

Table I

\section{Fragmentation vs dozer productivity (Hayes,} 1997)

\begin{tabular}{|c|c|c|c|}
\hline \multicolumn{4}{|c|}{ Productivity (bcm/hour) } \\
\hline $\begin{array}{c}\text { Push Distance } \\
(\mathrm{m})\end{array}$ & $\begin{array}{c}\text { Poor } \\
\text { Fragmentation }\end{array}$ & $\begin{array}{c}\text { Medium } \\
\text { Fragmentation }\end{array}$ & $\begin{array}{c}\text { Good } \\
\text { Fragmentation }\end{array}$ \\
\hline 30.4 & 716.25 & 860 & 1100 \\
\hline 60.9 & 370 & 477.5 & 573 \\
\hline 91.4 & 238 & 300 & 390 \\
\hline 121.9 & 191 & 238 & 334 \\
\hline 152.4 & 170 & 191 & 286 \\
\hline & & & \\
\hline
\end{tabular}

Productivity as a Percentage of "Good Fragmentation"

\begin{tabular}{|c|c|c|c|}
\hline \multicolumn{3}{|c|}{ Productivity as a Percentage of "Good Fragmentation" } \\
\hline $\begin{array}{c}\text { Push Distance } \\
(m)\end{array}$ & $\begin{array}{c}\text { Poor } \\
\text { Fragmentation }\end{array}$ & $\begin{array}{c}\text { Medium } \\
\text { Fragmentation }\end{array}$ & $\begin{array}{c}\text { Good } \\
\text { Fragmentation }\end{array}$ \\
\hline 30.4 & $65 \%$ & $78 \%$ & $100 \%$ \\
\hline 60.9 & $65 \%$ & $83 \%$ & $100 \%$ \\
\hline 91.4 & $61 \%$ & $77 \%$ & $100 \%$ \\
\hline 121.9 & $57 \%$ & $71 \%$ & $100 \%$ \\
\hline 152.4 & $59 \%$ & $67 \%$ & $100 \%$ \\
\hline Overall Average & $61 \%$ & $75 \%$ & $100 \%$ \\
\hline $\begin{array}{c}\text { Average for } 60- \\
91 m \text { PD }\end{array}$ & $63 \%$ & $\mathbf{8 0} \%$ & $\mathbf{1 0 0} \%$ \\
\hline
\end{tabular}

that, the information in Table I is based on a Cat D11 dozer model from 1997. It has been assumed that since 1997, the Cat D11's production and performance capabilities have increased with improved technology and further optimization. Given this, it was reasonable to assume that a modern dozer could perform better with the same level of fragmentation, and therefore a higher production factor than 0.8 and 0.63 was associated with medium and coarse fragmentation respectively.

Using this data as well as mine site data and operator testimonials, the following factors were applied and defined.

\section{> Fine fragmentation production factor: 1.00}

- Refers to standard blasted material associated with easy digging and good blade fill factor.

- Medium fragmentation production factor: 0.85

- Associated with more uniform particle size and sharper edges, increasing the difficulty of filling the blade and digging the material.

- Coarse fragmentation production factor: 0.7

- Defined by a skewed distribution of particle sizes containing larger fragments with sharp edges, typically associated with low blade fill factor and ‘jolty' diggability.

\section{Muckpile profile}

Three different muckpile profiles were established, which were defined by the amount of waste material that falls behind the 'pivot line' as prime material (i.e. does not need to be rehandled).

> A small cast blast leaves the most material up against the highwall and casts only $15 \%$ of the material behind the pivot line

> A medium cast blast casts approximately $20 \%$ of the material behind the pivot line and leaves less material against the highwall

> A large cast blast typically generates a large power trough, casting $25 \%$ of the material behind the pivot line and throwing approximately one-third of the material off the highwall.

Figures 4, 5, and 6 illustrate the three different muckpile profiles.

\section{Excavator size}

The following excavator sizes were selected to reflect the mine's excavator conditions as well as the field case studies explored in the literature.

> Hitachi EX2600 excavator fitted with a $15 \mathrm{~m}^{3}$ bucket

> Caterpillar 5130b excavator fitted with a $23 \mathrm{~m}^{3}$ bucket

> Hitachi EX3600 excavator fitted with a $29 \mathrm{~m}^{3}$ bucket.

\section{Calculation of the dozer side-cutting production factor}

\section{Overview}

Data was obtained and analysed from a mine site in NSW that performs dozer side-cutting on the highwall. A sidecutting factor of 0.75 was determined (i.e. $25 \%$ of production time was spent side-cutting the highwall). The data was provided in the form of a Microsoft Excel document which was compiled from GPS-tracked dozers. 


\section{Dozer 'side-cutting' versus excavator side-casting on the highwall in dozer bulk push operations}

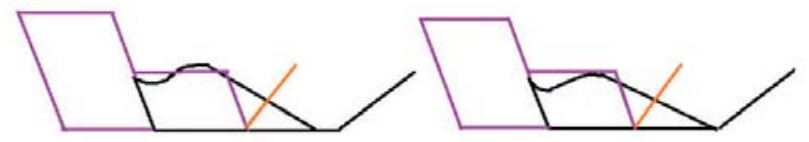

Figure 4-Small muckpile profile

Figure 5-Medium muckpile profile

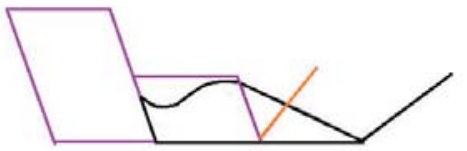

Figure 6-Large muckpile profile

A seven-day period was analysed and the data manipulated. Due to confidentiality agreements, the location of the site was not provided and therefore an assumption regarding the coordinates of the highwall was made. It was assumed that in accordance with a typical bulk pushing operation, the direction in which dozers travel the most is perpendicular to the highwall when bulk-pushing material.

Inputs

The data collected from the dozers included the time, task, and easting, northing, and elevation coordinates. The 'task' values were broken up into commands the operators could select on their dozer screens to describe the following activities:

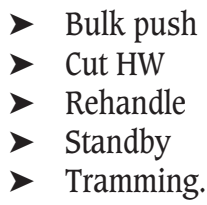

A sample of the format and data required is outline in Table II (a full version can be provided upon request).

\section{Calculation method}

The following steps were undertaken to determine the amount of time over the seven-day period that dozers spent on the highwall. The major underlying assumption made throughout the process was that the time spent working in the direction parallel to the highwall was deemed as 'sidecutting' time, and that spent working in the direction perpendicular to the wall was deemed as 'bulk pushing' time.

> The number of instances the dozer was oriented in a direction between $0^{\circ}$ and $90^{\circ}$ and between $180^{\circ}$ and $270^{\circ}$ was determined.

> The number of instances the dozer was oriented in a direction between $90^{\circ}$ and $180^{\circ}$ and between $270^{\circ}$ and $360^{\circ}$ was determined.

> Assuming that the dozer works in one direction most of the time (when bulk pushing), the higher number of

\section{Table II}

\section{Side-cutting data sample}

\begin{tabular}{|c|c|c|c|c|c|c|c|c|}
\hline $\begin{array}{c}\text { Rows/ } \\
\text { Columns }\end{array}$ & A & B & C & D & E & F & G & H \\
\hline & Date & Time & $\begin{array}{c}\text { Delta } \\
\text { Time }\end{array}$ & Task & East & North & Elevation & Direction \\
\hline 1 & $4 / 16 / 2014$ & $9: 00: 00$ & 0 & Pushing & 7.52 & 8730.66 & 8821.31 & 1 \\
\hline 1 & 1 & $\vdots$ & $\vdots$ & $\vdots$ & $\vdots$ & $\vdots$ & 1 & $\vdots$ \\
\hline 73151 & $4 / 23 / 2014$ & $8: 59: 58$ & 2.433 & $\begin{array}{c}\text { Bulk } \\
\text { Push }\end{array}$ & 2.27 & 8622.98 & 8577.30 & 0 \\
\hline
\end{tabular}

instances provided the dozer direction and therefore the direction of the highwall strike.

> The average direction in each instance was determined, which provided a highwall strike at $49^{\circ} \mathrm{N}$ and therefore a dozer bulk push direction at $310^{\circ} \mathrm{N}$.

> The time spent working in each direction was determined, which showed a total of 153741 seconds spent parallel to the highwall out of a total time of 604 798 seconds, suggesting that dozers spent $25 \%$ of the time side-cutting the highwall. This suggested a sidecutting production factor of 0.75 .

These results were verified by checking the number of times the dozer operators made use of their controllers and pressed 'Cut HW' when side-cutting the highwall. Times when the dozers were on standby or not moving were filtered out. Over the first twelve-hour shift, $22.5 \%$ of the time was spent cutting the highwall. The following couple of days found an average of $49 \%$ for one dozer and 30\% for another. Overall, the seven-day average was $35 \%$.

While this suggests that a production factor lower than 0.75 should be applied, these results rely on the operators to accurately and consistently record their activities when operating. Because of this, these results are less accurate than could be the case. However, the first twelve-hour shift could potentially be a better representation of the side-cutting time, assuming their operators were more diligent in correctly pressing the controllers on the first day. After several shifts of repeating the dozer push process, it is reasonable to assume the operators would begin to forget to adjust their activities on the controller, which would therefore over-state their time side-cutting the highwall. While these results still provide an idea of potential side-cutting productivity loss, a factor of 0.75 based on the calculation steps listed above was selected.

\section{Design process}

Using design software, blasted bench profiles for each different bench width and each different muckpile profile were designed. The following steps were taken to design the scenarios.

> Each bench profile was designed with a $70^{\circ}$ highwall. The bottom $8 \mathrm{~m}$ of each design was assumed to be more economical to handle by truck and shovel methods and was therefore left out (Boulton, 2016).

> The pivot line was drawn from the edge and toe of the bench floor at $53^{\circ}$ from the horizontal.

> The area (to be placed behind the pivot line) associated with each different muckpile profile was calculated.

> The remaining blasted profile was designed to replicate that of the corresponding muckpile profile.

> Each profile was then broken up into multiple slices (for the design scenarios that assumed an excavator was used on the highwall, a $12 \mathrm{~m}$ section from the highwall was allocated to the excavator and the remaining profile was then broken into slices).

> Using standard cut-and-fill design procedures, the volume of each slice was replicated on the low wall side of the profile.

> The centroid of each 'cut' and 'fill' section was calculated in order to determine the average grade and distance the dozers had to travel throughout the operation. 


\section{Dozer 'side-cutting' versus excavator side-casting on the highwall in dozer bulk push operations}

Figures 7, 8, and 9 are examples of the three different muckpile profiles for a $55 \mathrm{~m}$ bench width (all designs can be provided upon request). The larger cast blast profile results in more material behind the pivot line and less material on the highwall than the medium and small cast blast profiles.

\section{Dozer and excavator costs}

The costs associated with a Hitachi EX3600 excavator fitted with a $29 \mathrm{~m}^{3}$ bucket were obtained from the mine site, while the costs of a Hitachi EX2600 and a Caterpillar 5130b excavator were obtained from MEC Mining. An opportunity cost of 1.25 was applied to the EX3600 excavator to reflect the lost production time the excavator would otherwise use performing higher priority tasks around the mine.

Table III outlines the costs associated with the dozers and the different sized excavators.

\section{Cost and productivity calculator}

A cost and productivity model was generated using the inputs and variables for each design scenario. For each design that assumed an excavator worked the highwall, the cost of using the excavator generated from the excavator model was added

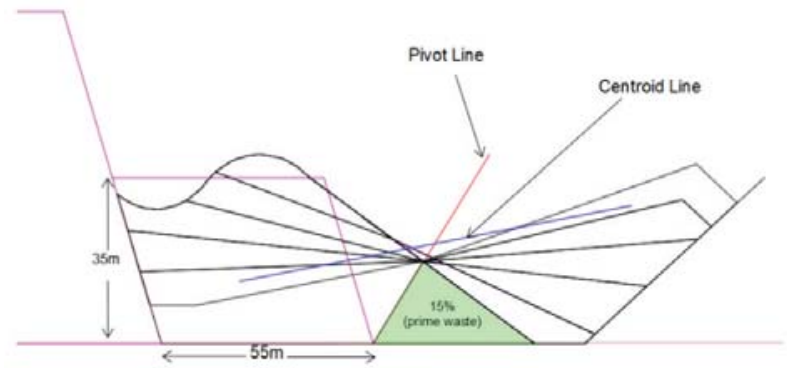

Figure 7-Small muckpile profile design without excavator assistance on $55 \mathrm{~m}$ bench

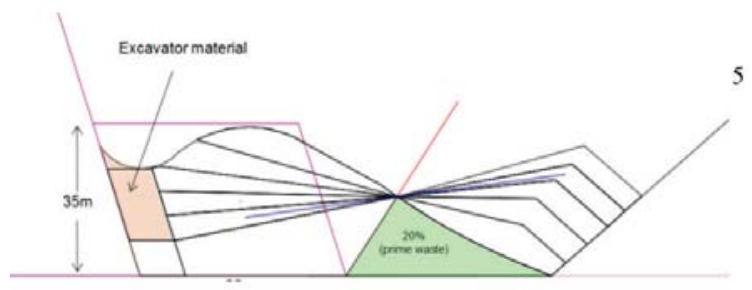

Figure 8-Medium muckpile profile design without excavator assistance on $55 \mathrm{~m}$ bench

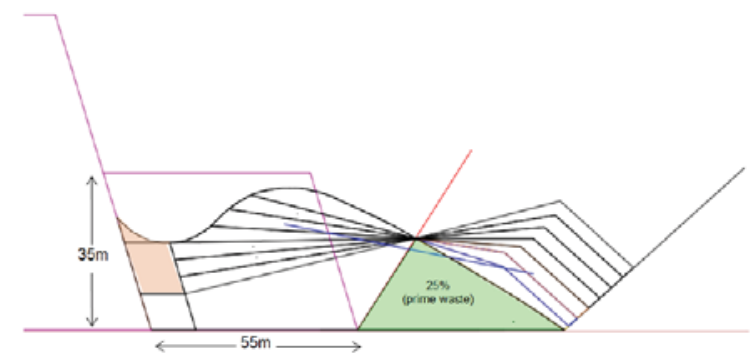

Figure 9-Large muckpile profile design without excavator assistance on $55 \mathrm{~m}$ bench
Table III

\section{Dozer and excavator costs}

\begin{tabular}{ccccc}
\hline & $\begin{array}{c}\text { CAT } \\
\text { D11R } \\
\text { Dozer }\end{array}$ & $\begin{array}{c}\text { Hitachi } \\
\text { EX2600 }\end{array}$ & $\begin{array}{c}\text { CAT 5130b } \\
\text { Excavator }\end{array}$ & $\begin{array}{c}\text { Hitachi } \\
\text { EX3600 } \\
\text { Excavator }\end{array}$ \\
\hline $\begin{array}{c}\text { Total Operating Cost } \\
\text { (excl. Labour) (\$) }\end{array}$ & $1,159,646$ & $3,294,400$ & $3,736,523$ & $4,950,551$ \\
$\quad \begin{array}{c}\text { Total Labour cost (\$) } \\
\quad 800,977\end{array}$ & 406,560 & 448,640 & 582,649 \\
$\quad \begin{array}{c}\text { Total Operating } \\
\text { Hours }\end{array}$ & 5,323 & 3,872 & 3,872 & 4,500 \\
$\begin{array}{c}\text { Total Cost per } \\
\text { Operating Hour (\$) }\end{array}$ & 367 & 956 & 1,081 & 1,537 \\
\hline
\end{tabular}

to the cost of the design generated from the dozer calculator model. Once an overall cost was assigned to each design, the total cost per LCM was determined.

\section{Dozer model}

Equations [1] and [2] were applied to each design combination to determine the productivity and cost of each scenario. Using the average push distances and grades of each slice in a design, the theoretical maximum productivity was obtained from the Caterpillar Performance Handbook.

$$
\begin{aligned}
\text { Productivity (per slice) } & \\
& =\mathrm{ThP} \times \mathrm{TF} \times \text { DoF } \times \mathrm{OF} \times \mathrm{DeF} \times \mathrm{MF} \\
& \times \mathrm{FF} \times \mathrm{SF}
\end{aligned}
$$

where:

Thp $=$ Theoretical maximum productivity (LCM/h)

$\mathrm{TF}=$ Traction factor

DoF $=$ Dozing factor

$\mathrm{OF}=$ Operator factor

DeF $=$ Density factor

$\mathrm{MF}=$ Material factor

$\mathrm{FF}=$ Fragmentation factor

$\mathrm{SF}=$ Sidecutting factor

$$
\begin{aligned}
\text { Total Cost }(\mathrm{A} \$)= & \sum_{\substack{i \\
\text { Productivity }(\mathrm{LCM} / \mathrm{h})}} \frac{\text { Volume }(\mathrm{LCM})}{\text { Tot Cost per Operating Hour }}
\end{aligned}
$$

where:

$\mathrm{n}=$ number of slices per design scenario

\section{Excavator model}

When generating the excavator cost and productivity model, several assumptions were made:

> The Hitachi EX3600 operates for approximately 4500 hours per year, while the other two smaller loading units operate for 3873 hours per year

> All loading units walk to and from the operation between each pass to fulfil other mining tasks on site

> Walking time is approximately 4 hours each way

> Bucket fill factors vary depending on fragmentation

> A job efficiency factor of $91 \%$ represents an average of 54 to 55 minutes per hour of efficient working by the excavators.

The trenching productivities under different fragmentation conditions for each size of excavator were obtained from the trenching chart in the Caterpillar Performance Handbook (2008).

Equation [3] was used to calculate the total cost of using the respective excavators in the dozer push operations. 


\section{Dozer 'side-cutting' versus excavator side-casting on the highwall in dozer bulk push operations}

$$
\text { Cost }(\$)=\left[\left(\frac{\text { Volume }}{\left.\operatorname{TrP}\left(\begin{array}{l}
\text { LCM } / h) \times \mathrm{JEF} \\
\times \text { Operating cost } / \mathrm{h}
\end{array}\right)+\text { Walking time }\right]}\right.\right.
$$

where:

$\operatorname{TrP}=$ Trenching productivity (LCM per60-minute hour) $\mathrm{JEF}=$ Job efficiency factor

A sample of the excavator and dozer cost calculator models that were developed can be seen in Figures 10 and 11.

\section{Project results and analysis}

\section{Cost analysis - $45 \mathrm{~m}$ bench width}

Figure 12 shows the conditions under which dozer sidecutting is economically favourable for a bench width of $45 \mathrm{~m}$. For a large cast blast with fine or medium fragmentation, dozer side-cutting is cheaper than using any excavator in the operation. However, in the case of a big cast with coarse fragmentation, dozer side-cutting is only more economical compared to the use of the largest size excavator $\left(29 \mathrm{~m}^{3}\right.$ bucket). This is also the case for a medium cast blast with fine and medium fragmentation, as well as a small cast blast with fine fragmentation.

Table IV outlines the potential cost savings by having the dozers side-cut the highwall rather than using an excavator. Higher cost savings for a $45 \mathrm{~m}$ bench seem to occur for larger cast blasts and finer fragmentation.

\section{Cost analysis - $55 \mathrm{~m}$ bench width}

For a bench width of $55 \mathrm{~m}$, Figure 13 shows the three occasions for which dozer side-cutting is more economical. For sites with smaller excavators equivalent to a Hitachi EX2600 or Caterpillar 5230b, having the excavators side-cast the material off the highwall would be more economical in all conditions. However, for sites restricted to using a larger excavator with a $29 \mathrm{~m}^{3}$ bucket, like at the mine site investigated, dozer side-cutting is cheaper for big casts with fine and medium fragmentation, as well as for medium casts with fine fragmentation.

Table V shows the potential cost savings when the dozers side-cut the material instead of the $29 \mathrm{~m}^{3}$ bucket excavator

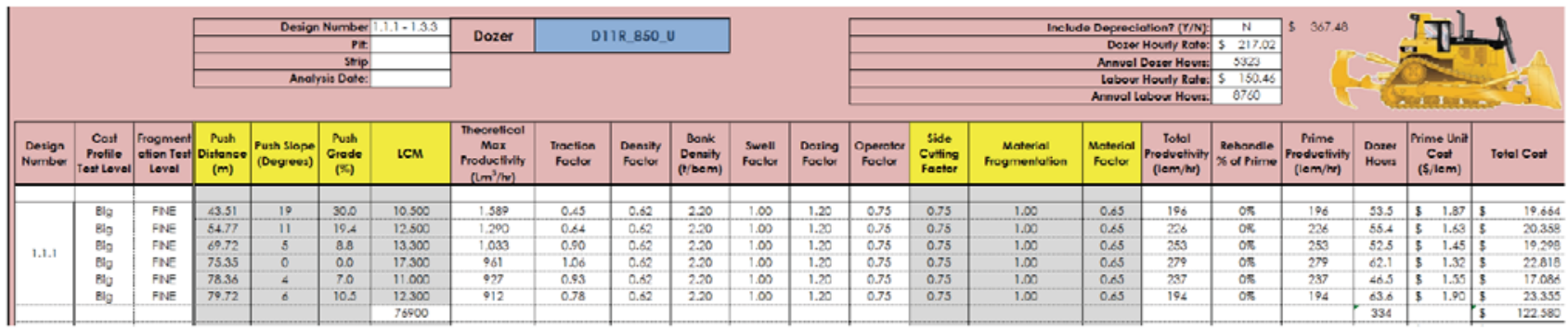

Figure 10-Snapshot of the dozer cost calculator model developed

\begin{tabular}{|c|c|c|c|c|c|c|c|c|c|c|c|}
\hline $\begin{array}{l}\text { Design } \\
\text { Number }\end{array}$ & Fragmentation & LCM & $\begin{array}{c}\text { Loader } \\
\text { Bucket } \\
\text { Capacity } \\
\text { (LCM) }\end{array}$ & $\begin{array}{l}\text { Bucket } \\
\text { Payload }\end{array}$ & $\begin{array}{l}\mathrm{LCM} / 60 \\
\min \text { hour }\end{array}$ & $\begin{array}{l}\text { Job } \\
\text { Efficiency } \\
\text { Factor }\end{array}$ & $\begin{array}{c}\text { Total } \\
\text { Productivity } \\
\text { (lcm/hr) }\end{array}$ & $\begin{array}{l}\text { Loader } \\
\text { Hours } 1\end{array}$ & $\begin{array}{l}\text { Loader } \\
\text { Hours } \\
\text { (with } \\
\text { walking) }\end{array}$ & $\begin{array}{l}\text { Loader } \\
\text { Unit Cost } \\
(\$ / \mathrm{lcm})\end{array}$ & $\begin{array}{l}\text { Total } \\
\text { Cost }\end{array}$ \\
\hline 4.1 .1 .1 & Fine & 15,485 & 15 & 15.75 & 1.924 & 0.91 & 1,751 & 9 & 49 & 3.02 & $\$ 46,688$ \\
\hline 4.1 .1 .2 & Medium & 15,485 & 15 & 14.25 & 1,721 & 0.91 & 1,566 & 10 & 50 & 3.08 & $\$ 47,682$ \\
\hline 4.1 .1 .3 & Course & 15,485 & 15 & 12.75 & 1,519 & 0.91 & 1,382 & 11 & 51 & 3.16 & $\$ 48,942$ \\
\hline 4.1 .2 .1 & Fine & 22,300 & 15 & 15.75 & 1,924 & 0.91 & 1,751 & 13 & 53 & 2.26 & $\$ 50,409$ \\
\hline 4.1 .2 .2 & Medium & 22,300 & 15 & 14.25 & 1,721 & 0.91 & 1,566 & 14 & 54 & 2.32 & $\$ 51,841$ \\
\hline 4.1 .2 .3 & Course & 22,300 & 15 & 12.75 & 1.519 & 0.91 & 1,382 & 16 & 56 & 2.41 & $\$ 53.656$ \\
\hline 4.1 .3 .1 & Fine & 25,300 & 15 & 15.75 & 1.924 & 0.91 & 1.751 & 14 & 54 & 2.06 & $\$ 52,047$ \\
\hline 4.1 .3 .2 & Medium & 25,300 & 15 & 14.25 & 1.721 & 0.91 & 1.566 & 16 & 56 & 2.12 & $\$ 53,672$ \\
\hline 4.1.3.3 & Course & 25,300 & 15 & 12.75 & 1,519 & 0.91 & 1,382 & 18 & 58 & 2.20 & $\$ 55,730$ \\
\hline
\end{tabular}

Figure 11-Snapshot of the excavator cost calculator model developed

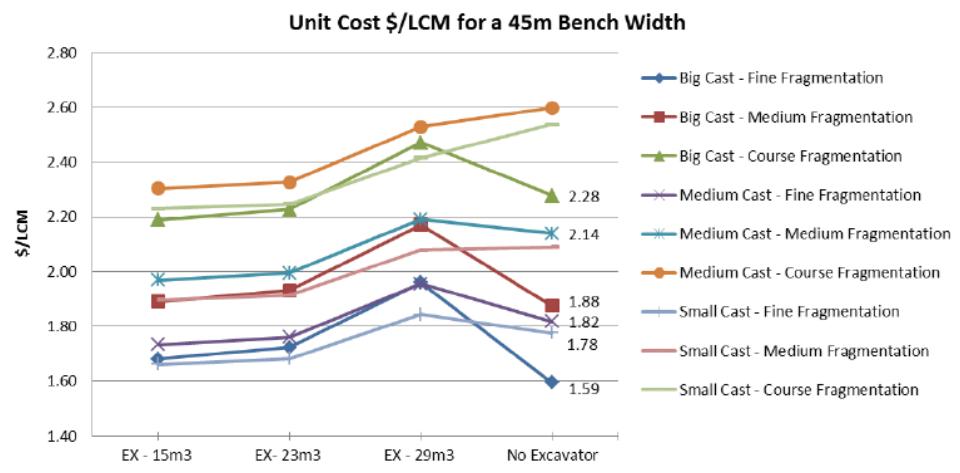


Table IV

\section{Cost savings when using dozer side-cutting technique on a $45 \mathrm{~m}$ bench}

\begin{tabular}{c|c|c|c}
\hline $\begin{array}{c}\text { Loader Bucket } \\
\text { Size }\end{array}$ & $\begin{array}{c}\text { Muckpile } \\
\text { Profile }\end{array}$ & Fragmentation & $\begin{array}{c}\text { Cost Savings } \\
(\mathbf{S} / \mathbf{l c m})\end{array}$ \\
\hline \multirow{2}{*}{$15 \mathrm{~m}^{3}$} & Big Cast & Fine & 0.09 \\
& Big Cast & Medium & 0.01 \\
\hline \multirow{3}{*}{$23 \mathrm{~m}^{3}$} & Big Cast & Fine & 0.13 \\
& Big Cast & Medium & 0.06 \\
\hline \multirow{5}{*}{$29 \mathrm{~m}^{3}$} & Big Cast & Fine & 0.37 \\
& Big Cast & Medium & 0.29 \\
& Big Cast & Course & 0.19 \\
\hline & Medium Cast & Fine & 0.14 \\
& Medium Cast & Medium & 0.05 \\
\hline & Low/Standard & Fine & 0.07 \\
\hline
\end{tabular}

side-casting the material. Once again, larger muckpile profiles and finer fragmentation offer higher cost savings.

\section{Cost analysis $-60 \mathrm{~m}$ bench width}

Figure 14 show that dozer side-cutting is more economical than using any excavator in a dozer push operation at any level of fragmentation for a standard/small muckpile profile.

As opposed to the results for bench widths of $45 \mathrm{~m}$ and $55 \mathrm{~m}$, higher cost savings are incurred for smaller muckpile profiles and finer fragmentation. Such cost savings are outlined in Table VI.

Figure 15 is the decision matrix created by compiling the cost analysis results from the project. It serves as a clear and practical tool for mine sites trying to decide whether to use an excavator during their dozer push operation, according to the bench dimensions, excavator size, muckpile profile, and fragmentation conditions.
Table V

\section{Cost savings when using dozer side-cutting technique on a $55 \mathrm{~m}$ bench}

\begin{tabular}{cccc}
\hline $\begin{array}{c}\text { Loader Bucket } \\
\text { Size }\end{array}$ & $\begin{array}{c}\text { Muckpile } \\
\text { Profile }\end{array}$ & Fragmentation & $\begin{array}{c}\text { Cost Savings } \\
(\$ / / \mathrm{cm})\end{array}$ \\
\hline \multirow{2}{*}{$29 \mathrm{~m}^{3}$} & Big Cast & Fine & 0.16 \\
& Big Cast & Medium & 0.07 \\
& Medium Cast & Fine & 0.03 \\
\hline
\end{tabular}

\section{Trends}

The results revealed some trends between variables. As expected, unit cost and productivity decreased with finer fragmentation. Figure 15 highlights the relationship between the muckpile size and the shape of the profile and bench width. It seems that for a bench width of $45 \mathrm{~m}$, dozer sidecutting is economically favourable for large muckpile profiles; however, for a $60 \mathrm{~m}$ bench, it is favourable for small/standard blast profiles. This relationship shows that the unit cost is much more sensitive to the amount of material left against the highwall than it is to the additional push distance the dozers must travel due to a wider bench. The results suggest that for a bench width of $45 \mathrm{~m}$ and a large cast blast, is not worthwhile using an excavator to clear the small volume of material left against the highwall. Evidently, the production loss associated with dozer sidecutting is small enough to outweigh any production gain from an excavator. The shorter push distance associated with the smaller bench width of $45 \mathrm{~m}$, as well as the small amount of material on the highwall, proved to be ideal conditions for dozer side-cutting. However, for a bench width of $60 \mathrm{~m}$, dozer side-cutting is no longer economically favourable for

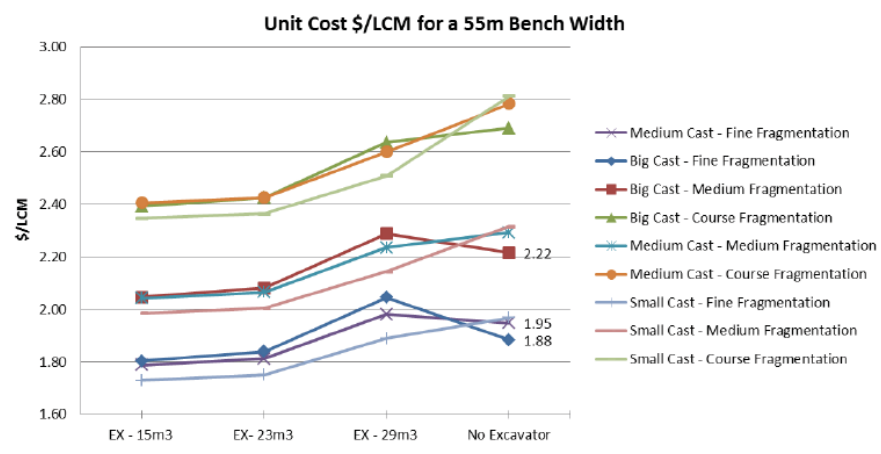

Figure 13-Unit cost (\$ per LCM) for a $55 \mathrm{~m}$ bench width

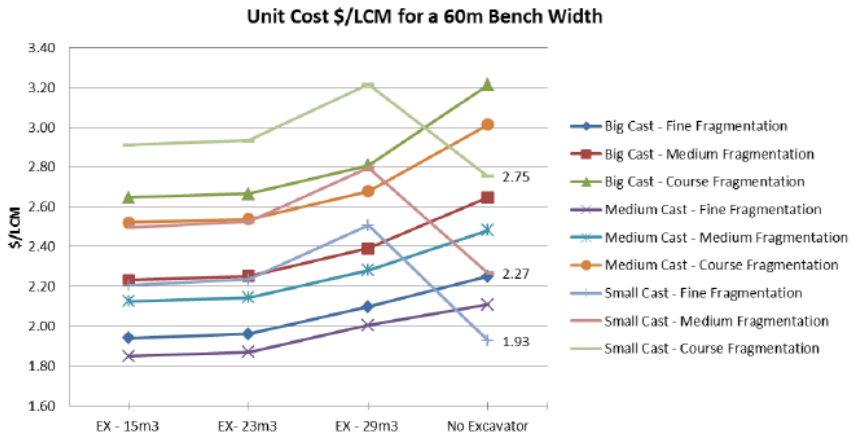

Figure 14-Unit cost (\$ per LCM) for a $55 \mathrm{~m}$ bench width 


\section{Table VI}

\section{Cost savings when using dozer side-cttuing technique on a $60 \mathrm{~m}$ bench}

\begin{tabular}{cccc}
\hline $\begin{array}{c}\text { Loader Bucket } \\
\text { Size }\end{array}$ & $\begin{array}{c}\text { Muckpile } \\
\text { Profile }\end{array}$ & Fragmentation & $\begin{array}{c}\text { Cost Savings } \\
(\$ / \mathbf{l c m})\end{array}$ \\
\hline \multirow{3}{*}{$15 \mathrm{~m}^{3}$} & Low/Standard & Fine & 0.28 \\
& Low/Standard & Medium & 0.23 \\
& Low/Standard & Course & 0.16 \\
\hline \multirow{2}{*}{$23 \mathrm{~m}^{3}$} & Low/Standard & Fine & 0.31 \\
& Low/Standard & Medium & 0.26 \\
& Low/Standard & Course & 0.18 \\
\hline \multirow{2}{*}{$29 \mathrm{~m}^{3}$} & Low/Standard & Fine & 0.58 \\
& Low/Standard & Medium & 0.53 \\
& Low/Standard & Course & 0.46 \\
\hline
\end{tabular}

this large cast blast profile. The longer push distance on a $60 \mathrm{~m}$ bench outweighs the benefits of the small production gain associated with having the dozers side-cut the small amount of material left on the highwall. Evidently, the production gain in using an excavator renders the operation cheaper.

Nevertheless, for a $60 \mathrm{~m}$ bench width with a small cast blast profile, dozer side-cutting becomes more economical. A small muckpile profile results in much more material being left on the highwall than other muckpile profiles. Evidently, the costs of removing this increased amount of highwall material with an excavator exceed the costs associated with the production loss due to having the dozers side-cut instead, as well as the production loss caused by the longer push distance. Therefore, while dozer side-cutting is less economical with increasing bench width (push distance), using an excavator is even less economical with decreasing muckpile size.

Overall, a bench width of $45 \mathrm{~m}$ provided the most opportunities for dozer side-cutting to replace the use of an excavator, in particular for large cast blasts and finer fragmentation. Finally, dozer side-cutting proved to be more economical than the use of the Hitachi EX3600 in more conditions than the use of the two smaller excavators.

\section{Cost sensitivity analysis}

A sensitivity analysis was conducted in terms of the number of instances that dozer side-cutting became economical, taking into consideration:

- Excavator operating costs

> Dozer operating costs

> The dozer side-cutting factor

- Fragmentation factors

> The number of hours allocated to excavator walking time.

It was found that a $2 \%$ change in excavator operating costs and the amount of walking time for the excavator had the most effect, whereby the number of instances dozer sidecutting became more or less economical changed by approximately three. It wasn't until a 5\% change in the dozer side-cutting factor or a $7 \%$ change in fragmentation levels that the number of instances changed by one.

\section{Conclusions}

A mine site in the Hunter Valley was used as a case study to investigate the effect of muckpile profile, fragmentation, bench width, and excavator size on the cost of using an excavator to assist a typical bulk push operation. To remove the material that rests against the highwall after a bench has been blasted, an excavator can be used to side-cast the waste, which allows the dozers to immediately begin bulk pushing into the spoil pile. An alternative technique involves the dozers working parallel to the highwall and 'side-cutting' this material before rotating their blades to begin the bulk pushing process perpendicular to the highwall. Current industry practices suggest dozer side-cutting is less productive and economical than using excavator assistance. Nevertheless, this research project aimed to identify the mining conditions under which each technique could be more economically viable.

An extensive literature review was conducted, investigating the dozer bulk push production factors as well as analysing relevant industry case studies. The review identified a lack of information and research in the following areas:

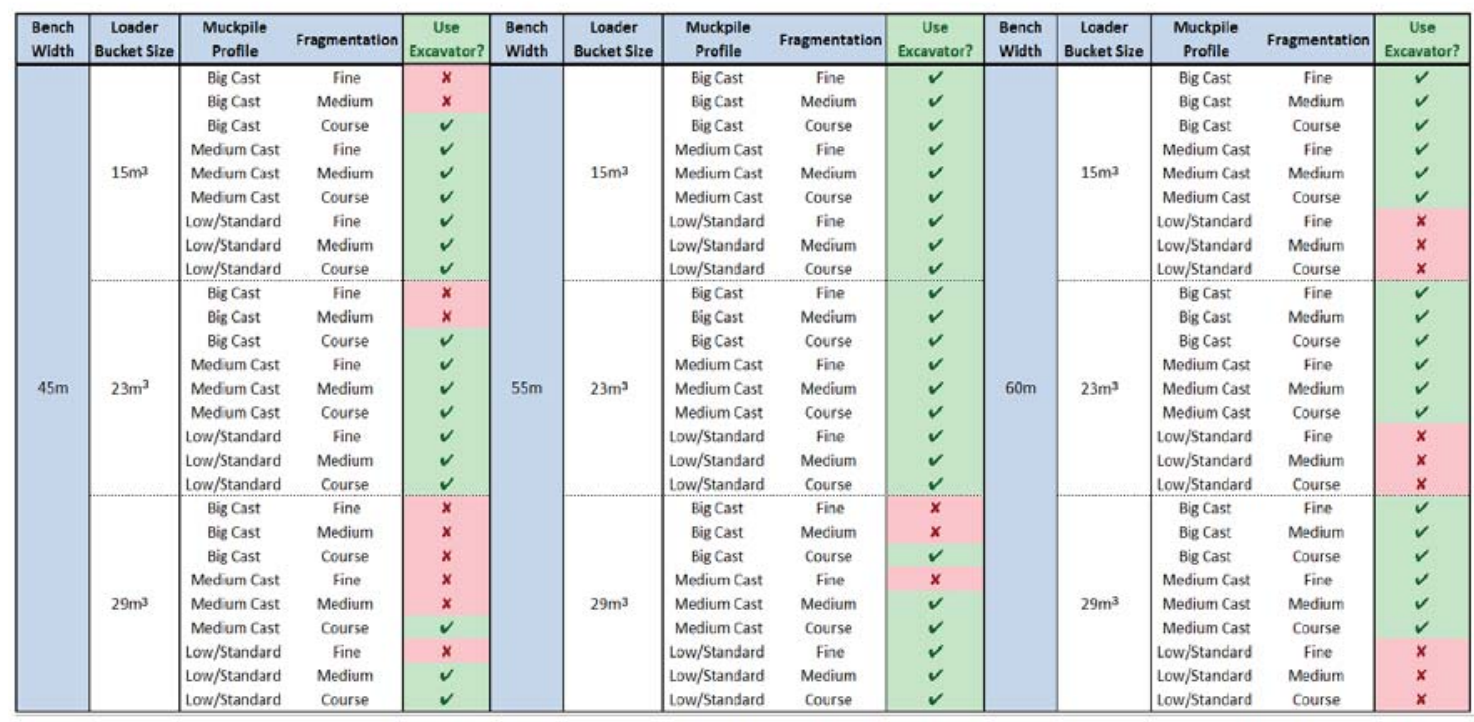




\section{Dozer 'side-cutting' versus excavator side-casting on the highwall in dozer bulk push operations}

Dozer bulk push productivity and costs in terms of muckpile profiles and fragmentation

- Excavator-assisted dozer push operations for excavators fitted with buckets larger than $23 \mathrm{~m}^{3}$

> The productivity loss when dozers side-cut the highwall (the dozer side-cutting production factor).

To investigate these factors, 109 different dozer bulk push designs were developed which tested the following variables:

- Muckpile profile (large, medium, and standard/small)

- Fragmentation (fine, medium, and coarse)

> Bench width (45 m, $55 \mathrm{~m}$, and $60 \mathrm{~m}$ )

> Excavator size $\left(15 \mathrm{~m}^{3}, 23 \mathrm{~m}^{3}\right.$, and $29 \mathrm{~m}^{3}$ buckets).

Dozer bulk push data was obtained from a mine in NSW and was analysed and used to calculate a dozer side-cutting production factor of 0.75 (the dozers had spent approximately $25 \%$ of the time cutting the highwall throughout the operation). Out of 81 scenarios, the results showed 22 instances when dozer side-cutting was more economical than using an excavator. For a $45 \mathrm{~m}$ bench width, larger blast profiles and finer fragmentation proved to be ideal, especially compared to the use of the larger excavator (Hitachi 3600 with a $29 \mathrm{~m}^{3}$ bucket). For a $55 \mathrm{~m}$ bench width, dozer side-cutting was preferable to using the larger excavator only; while for a $60 \mathrm{~m}$ bench dozer side-cutting was more viable than the use of an excavator of any size in small blast profile conditions for any level of fragmentation.

The cost savings achieved by using dozer side-cutting ranged between $\$ 0.06$ per LCM and $\$ 0.59$ per LCM. The $60 \mathrm{~m}$ bench width with a small muckpile profile showed the largest cost savings where an all dozer operation cost between $\$ 1.92$ and $\$ 2.75$ per LCM for fine to coarse fragmentation respectively. In comparison, an excavator-assisted operation cost between $\$ 2.2$ and $\$ 2.51$ per LCM and \$2.91 and \$3.22 per LCM for medium and coarse fragmentation respectively, across the three different sized excavators. Furthermore, an inverse relationship between the size of the blast profile and the bench width was identified. The relationship highlighted that while dozer side-cutting became less economical with increasing bench width (push distance), using an excavator became even less economical with decreasing muckpile size.

The productivity of each scenario was determined and was found to support existing literature on dozer productivity. The excavator-assisted dozer operations were found to be on average 30\% more productive than the dozer side-cutting bulk push operation across each of the variables.

It should be noted that regardless of the results, mine sites could choose to use an excavator, irrespective of the costs, to avoid having the dozers work under the highwall. Another main deterrent for using dozer-side-cutting is the potential damage and maintenance costs on the dozers as well as the fact that an excavator provides cleaner highwall face conditions. Furthermore, dozer side-cutting could cause excessive exposure of operators to vibration, which could indicate another advantage to using an excavator.

\section{Further work}

This research project has validated the use of excavator sidecasting in certain dozer push conditions. However, further work is encouraged to verify the findings and draw additional conclusions. This could include:
Developing a financial technical model comparing the total unit costs (including capital expenditure) for an excavator-assisted dozer push operation versus a dozer sidecutting bulk push operation. This would be ideal for relatively new mine sites that wish to have a dedicated dozer bulk push fleet.

> Investigating and testing for potential damage and maintenance costs after dozers perform side-cutting.

> Obtaining more mine site data or conducting site trials to validate the dozer-side-cutting production factor.

> Investigating the optimal dozer side-cutting technique in itself in order to improve productivity and broaden the application of dozer side-cutting in the bulk push operation.

> Exploring the optimal conditions and developing optimal designs which use both the dozer side-cutting and excavator side-casting techniques in the same operation.

\section{Acknowledgements}

It is with great pleasure that the author acknowledges and thanks the following people personally for supporting this research project:

> Ted Boulton, MEC Mining

> David Hall, 3D Data Guidance

$>$ Dr Warren Seib

> Brendan O'Brien, Rio Tinto Coal Australia

> Timothy Booth, BHP Billiton

> Matt Kleinschmidt

$>$ Jake Young.

\section{References}

Aspinall, T.O., Davidson, C.W., Davies, A.L., Hagan, T.N. Isles, P.T., McManus, D.A., and Smith, G.H. 1993. Strip mining. Australia Coal Mining Practice Monograph 12. Martin, C.H. and Hargraves, A.J. (eds). Australasian Institute of Mining and Metallurgy, Melbourne. pp. 203-223.

Boulton, T. 2016. Personal communication. Director, MEC Mining, Brisbane. 30 June.

Boulton, T. 2015. Dozer push training: Design for optimal productivity. MEC Mining, Brisbane. 40 pp.

CAterPillar. 2008. Caterpillar performance handbook. Caterpillar, Peoria, IL. pp. $1-50-1-72$.

Cunningham, J. 2013. Economic optimisation of dozer push operations for typical open cut coal mines. Honours thesis, University of Queensland, Brisbane.

DоктAn, M., SсотT, A., and Cocker, A. 1998. Optimisation of dozer operations in open cut mines. JKMRC/ACARP Project C5008. Australian Coal Association Research Programme, Brisbane. pp. 89-105.

HaLl, D. 2016. Personal communication. Director, 3D Data Guidance. 7 May and 1 July.

Hartman R.L. 2001. Cat D11R Carrydozer vs Cat D11NU Blade Job Study 2. Caterpillar performance report, Caterpillar, Wyoming., pp 1-7.

HAYEs, T.G. 1997. Using dozers to remove coal overburden. Mining Engineering, vol. 49, no. 10. pp. 35-38.

InGLE, J., OATS JR, R.H., Humphrey, J.D., and Fung, N. 2005. Hydraluic excavator assisted dozer production method, Mining Engineering, vol. 57, no. 8. pp 45-50.

MEC MinING. 2015. Dozer bulk push training program presentation. Brisbane. pp 1-73

Veness, T. 2016. Personal communication. Drill and Blast Superintendent, Rio Tinto Coal Australia. 7 January.

SEIB, W. 2016. Personal communication. Consultant Lecturer, University of Queensland. 24 January.

Uren, Z. and Nehring, M. 2015 Development of dozer push optimisation software for Commodore coal mine. Mining Technology, vol. 124, no. 4. pp. 231-238. doi: 10.1179/1743286315Y.000000001. 